\title{
When East Meets West: Understanding the Misconduct of Teenage Girls in Hong Kong
}

\author{
Violet Cheung-Blunden*
}

Department of Psychology, University of San Francisco, San Francisco, CA 94117, USA

\begin{abstract}
Although acculturation towards western culture has been linked to higher levels of misconduct in previous research, little is understood about the mechanisms involved. The present study uses two mediators, early autonomy timetable and large family obligation discrepancy to explain how western values alter children's behavior and family dynamics, that would push them towards misconduct. The sample included 138 girls ( $M=13.8$ years) from Hong Kong, a former British colony. Results showed that when indigenous youths adopted western values, their autonomy timetables were accelerated, which in turn manifested itself as misconduct. Meanwhile, the western acculturated youths also had a larger discrepancy between parental expectation and a child's willingness to fulfill family obligations, and this discrepancy in turn became a source of misconduct. The two mediation pathways replaced the direct pathway, suggesting that the key intervention effort for problem behaviors in hybrid cultural settings ought to focus on autonomy timetable and obligation discrepancy rather than western influence per se.
\end{abstract}

Keywords: Misconduct, aggression, acculturation, autonomy timetable, family obligation.

\section{WHEN EAST MEETS WEST: UNDERSTANDING THE MISCONDUCT OF TEENAGE GIRLS IN HONG KONG}

As western influence extends across the globe, the social issues that accompany it are beginning to attract attention. Besides the use of tobacco, eating disorders and other chronic diseases [1-4], misconduct among youths seems to show a similar trend - European American children misbehave more than Asian immigrant children in the U.S., and western children in Hong Kong misbehave more than Chinese children in Hong Kong [5,6]. Transgressions range from copying homework to threatening teachers. Cultural variations in tolerating this kind of behaviors may offer some explanations, but laws and standards are more uniform across societies than once thought [7]. As technological advances and other globalization forces hasten the trend [8] there is an urgent need in hybrid societies to understand and intervene problem behavior.

The present paper proposes that the relationship between western acculturation and misconduct must be understood in order to inform intervention. Hong Kong, a well known instance of East meets West, may be a case in point. Although previous work has shown that acculturation towards western culture in Hong Kong was related to higher levels of misconduct in youths [9], little is understood about the mechanisms involved. Only when we know how western values alter behavior and family dynamics will we know why misconduct arises and what to do about it. The present

*Address correspondence to this author at the Department of Psychology, University of San Francisco, San Francisco, CA 94117, USA;

Tel: (415) 422-4373; Fax: (415) 422-2517;

E-mail: vcheung@usfca.edu study focuses on two mediators to examine the relationship between western acculturation and problem behavior.

\section{AUTONOMY TIMETABLE AS A MEDIATOR}

Materialism may stand front and center with regard to western culture, but the kernel of its value system is the primacy of the individual $[10,11]$. The prototype of a mature member of western society is independent, autonomous and free-spirited. In light of this, parents pursue this goal in terms of child-rearing techniques. The generally accepted practice is for parents to give their children responsibility for making small decisions, and then allow them to graduate to big decisions. Feldman and Rosenthal $[5,6]$ conducted several studies and showed that parents from Western cultures promote autonomy at an earlier age than parents from Asian cultures.

Of course, variability in the autonomy timetable exists within a culture and granting children too much freedom too quickly has been shown by past research to increase problem behavior. Early autonomy in children often entails family environments that offer low parental monitoring, and a lack of supervision may expose children to risk factors and give them more opportunities to engage in misconduct [12-15]. In a group of Chinese American adolescents, early autonomy correlated positively with misconduct [16]. Similar results were found in a mixed group of Caucasian and Asian high school students in Hong Kong, linking early autonomy to misconduct [17].

The currents of westernization elevate the importance of the individual in indigenous cultures such that youths will inevitably demand more independence. Yet, having a more aggressive autonomy timetable may expose them to risks that are no different from their western counterparts, such as 
a lack of parental supervision and more contact with crime. Therefore, the first hypothesis is that when youths in an indigenous culture acculturate towards western values, their autonomy tables are accelerated, which in turn manifests itself as misconduct. In other words, autonomy timetable mediates the relationship between western acculturation and misconduct.

\section{Obligation Discrepancy as a Mediator}

Another symptom that appears as youths embrace the idea of individualism is that they will spend less time dealing with family obligations and more time pursuing their own interests. This difference between Eastern and Western cultures has been used to measure individualismcollectivism. As children lag behind in family obligations in their parents' eyes, conflicts erupt. Regardless of the source of conflict, this type of family environment tends to be less accepting and more hostile to the child and eventually push them towards "outside influences" [15, 18-21]. For example, Ary et al. [13] found that high family conflict and low parent-child involvement contributed to problem behaviors in children.

Therefore, we postulate that another mediator between western acculturation and misconduct is the discrepancy of the family obligation. When youths in an indigenous culture acculturate towards western values, there is a larger discrepancy between parental expectation and a child's willingness to fulfill family obligations, and this discrepancy in turn becomes a source of misconduct.

Since two mediators have been proposed, we further hypothesize that the mediating pathways are relatively independent mechanisms. Moreover, the idea of mediation is to test whether the indirect pathways can effectively replace the direct pathway. A satisfactory model fit in the present case can be taken to mean that autonomy timetable and obligation discrepancy are sufficient explanations for why western acculturated youths misbehave, and intervention efforts ought to focus on these mediators.

\section{METHOD}

\section{Participants}

Participants were 138 Chinese girls ( $M=13.8$ years, $S D$ $=1.08$ ) from an all-girl campus and their parents (130 fathers and 131 mothers). The school was located on Hong Kong Island, which has a longer established colonial history than the other two districts, Kowloon and the New Territories. The school is a subsidized school, run by Christian organizations with government funding. It is the most prevalent type and constituted $95 \%$ of all schools in Hong Kong in the year 1999/2000 [22]. The teaching medium was English for all subjects except for Chinese and Chinese history. The school was able to demonstrate English proficiency, and obtained permission from the Education Commission to continue to use English as teaching medium.

The sample was recruited from three consecutive school grades (Form I, II, III) with a mean age of 12.81 years $(S D=$ $1.08), 13.49$ years $(S D=.56)$, and 14.61 years $(S D=.66)$, respectively. This age group was chosen because early teenage years mark a significant transition period from a dependent child to a more independent adolescent. In terms of socioeconomic status (SES), $17.8 \%$ of parents were from the upper, $45.8 \%$ the middle, $21.2 \%$ the working, and $15.3 \%$ the poverty class. Concerning living arrangements, $88.8 \%$ of the students resided in nuclear families and the rest in extended families, typically with grandparents, aunts and/or uncles. A majority of households were two-parent homes $(92.7 \%)$, and the remaining, single-parent homes $(7.3 \%)$.

Our sample seemed to represent the indigenous population, who had longer family history in Hong Kong. In the current Hong Kong population, only $57 \%$ of the people were born locally. In comparison, over $70 \%$ of the parents in our sample and all of the adolescents were local born.

\section{Instruments}

\section{Demographics of the Adolescents}

The adolescents provided information on their age, birth place, SES, district in Hong Kong when growing up, place of birth, length of stay in Hong Kong for non-locals, numbers of generations resided in Hong Kong, birth order, and their current living arrangement. Parents filled in portions of adolescent demographics if the adolescents felt unsure of certain information.

\section{Demographics of the Parents}

The parents provided information about their age, place of birth, place of growing up, length of stay in Hong Kong (for non-locals), occupation, religion, current family structure, education level and socio-economic class of their families of origin.

\section{Acculturation Measure [9,23]}

Forty-two items with high internal consistency were selected from Nguyen et al.'s study [23]. The original scale measured the level of involvement in American culture and the level of the involvement in Vietnamese culture separately. This scale was adapted to measure colonial residents in Hong Kong by Cheung-Blunden and Juang [9]. There were 21 items tapping into Chinese acculturation and 21 items tapping in Western acculturation, in the domains of food (2 items), entertainment (2 items), travel (2 items), group affiliation (6 items), and attitude towards cultures (9 items). Sample items include "The oldest girl in the family should help take care of the house and the younger children, whether she wants to or not" and "Daughters over the age of 18 should be allowed to move away from home, to go to college or to take a job somewhere else."

The response set was a 5-point Likert scale, with $1=$ strongly disagree and $5=$ strongly agree. Mean scores were calculated so that a higher score indicated more Chinese or Western acculturation. The internal consistency of the subscales reported by Nguyen et al. [23] was .92 for "acculturation Vietnamese culture" and .90 for "acculturation U.S. culture." The alpha coefficient for the present study was .82 for the Chinese subscale and .80 for the Western subscale.

\section{Behavioral Timetable of Autonomy [5]}

This is a 19-item scale that assessed the timetable of autonomous behaviors by asking what adolescents actually 
experienced with their parents. For example, "At what age were you allowed to choose your own hairstyle?" and "At what age would you have liked to choose your own hairstyle?' Participants rated each item on a 5-point scale: 1 $=$ before age $14 ; 2=14-15$ years; $3=16-17$ years; $4=18$ years or older; $5=$ never. Cronbach's alpha for the timetable was found to be .86 by Juang et al. [24] and the alpha value for this study was .78 .

\section{Family Obligations [25]}

All three subscales from the original version were used 1) current assistance to the family was measured by 11 items, 2) respect for the family was assessed by 7 items and 3) future support to the family as adults was tapped by 6 items. Sample items are, "Run errands that the family needs done," "Treat your parents with great respect" and "Have your parents live with you when they are older." A 5-point response scale was used, from "almost never" to "almost always" for the first subscale and "not important at all" to "very important" for the last two subscales. Mean scores were calculated so that a higher score indicated a stronger sense of family obligations.

These items were used twice, first measuring the students' attitude towards family obligation and then adolescents' report of their perceived parents' attitude. The discrepancy in family obligation was obtained by subtracting the adolescents' scores from the perceived parents' scores. Previous studies found the alpha coefficients for this scale to range from .69 to .85 [25]. For the present study, the alpha coefficient of adolescents' family obligation was .86 and the perceived parent family obligation was .90 .

\section{The Misconduct Scale [15]}

Adolescents responded to a 7-item scale concerning a range of problem behaviors from copying homework to threatening a teacher. A sample item is, "How often have you stolen from a store?" The response format was a 4-point scale ranging from $0=$ "never" to $3=$ "often." Mean scores were calculated so that a higher score indicated more misconduct. Alpha coefficients were between .82 and .86 in three groups of adolescents from the U.S., Hong Kong, and Australia [15]. The alpha for the present study was .81.

\section{Procedure}

The consent form and the survey were translated into Chinese by a professional translation agency in Hong Kong and the accuracy was verified twice, first by a bilingual Chinese in Hong Kong and then, a bilingual Chinese American.

The teachers at the high school were contacted and involved in all aspects of the research process from recruiting participants to administering the questionnaires. Adolescent participation was on a volunteer basis. Chinese parent/guardian consent forms and parents' own consent forms were distributed in the week prior to data collection to obtain signatures. The adolescent assent form and the survey were administered in classrooms of 20 to 30 students. Teachers introduced the survey as a psychological study of culture and adolescent development. The participants were instructed to use the class period to fill-out the survey. If students could not finish in time, they could continue to work on it at home. Adolescents were encouraged to clarify questions with the teachers. Those who did not participate were instructed to work on their homework. The average time taken to complete the survey was approximately 50 minutes. At the end of the session, the adolescents were asked to take the questionnaires home for parents to finish the child and parent demographic sections. The demographic information for adolescents could be filled out by either parent. Fathers and mothers separately answered questions about their background and current family. Teachers later collected the completed sets within the week.

\section{RESULTS}

Age might be a confounding variable in the upcoming mediation analysis if it bore significantly correlations with the independent variable, the mediators and the dependent variables. It could very well be the case that older children were more exposed to Western culture, enjoyed more autonomy, fulfilled more family obligation, and exhibited more problem behaviors. If the premise were true, results from the mediation analysis could be largely an artifact of the common age effect. SES could be another confound, if it correlated with all of the variables of interest, which would undermine the results of the mediation analysis.

Bivariate correlations were conducted to rule out these possibilities. Age was not a confounding variable as it showed no significant correlations with western acculturation $(r(133)=.17, \quad p=.051)$, autonomy timetable $(r(135)=-.01$, $p=.882)$, discrepancy in family obligation $(r(131)=.10$, $p=.269)$ or misconduct $(r(130)=.13, p=.147)$. Although the Pearson $r$ between age and western acculturation approached significance, it takes two or more significant correlations to amount to a confounding effect. SES was also ruled out as a confounding variable, as it showed no significant correlations with western acculturation $(r(136)=.05, p=.635)$, autonomy timetable $(r(133)=-.05, p=.646)$, discrepancy in family obligation $(r(132)=.17, p=.085)$ or misconduct $(r(134)=-.08, p=.387)$.

A first step in a mediation analyses was to ensure that the independent variable, mediators, and dependent variable were significantly correlated. Table 1 shows that western acculturated youths had earlier autonomy timetable $(r(123)=-$ $.25, p=.008)$, and earlier autonomy was associated with more misconduct $(r(126)=-.35, p=.000)$. Meanwhile, western acculturated youths also had a larger obligation discrepancy $(r(126)=.28, p=.003)$ and the discrepancy was related to more misconduct $(r(125)=.25, p=.008)$. It is also noteworthy that the two mediators, autonomy timetable and discrepancy of family obligations were not significantly correlated $(r(126)=-.03, p=.737)$, alluding to the independence between the two pathways.

A structural equation model is depicted in Fig. (1) based on the significant correlations in Table 1. Fig. (1) shows a direct pathway from western acculturation to misconduct and two indirect pathways - first via autonomy timetable and then via obligation discrepancy. This structural equation model would be tested, such that the direct pathway would be pivoted against the two indirect pathways in a model fit. 
Table 1. Intercorrelations among Main Study Variables

\begin{tabular}{|lllll|}
\hline & $\mathbf{1}$ & $\mathbf{2}$ & $\mathbf{3}$ \\
\hline 1. & Western Acculturation & -- & & \\
2. & Autonomy Timetable & $-.25^{* *}$ & - & \\
3. & Obligation Discrepancy & $.28^{* *}$ & -.03 & -- \\
4. & Misconduct & $.28^{* *}$ & $-.35^{* * *}$ & $.25^{* *}$ \\
\hline
\end{tabular}

Note. ${ }^{*} p<.05, * * p<.01, * * * p<.001$.

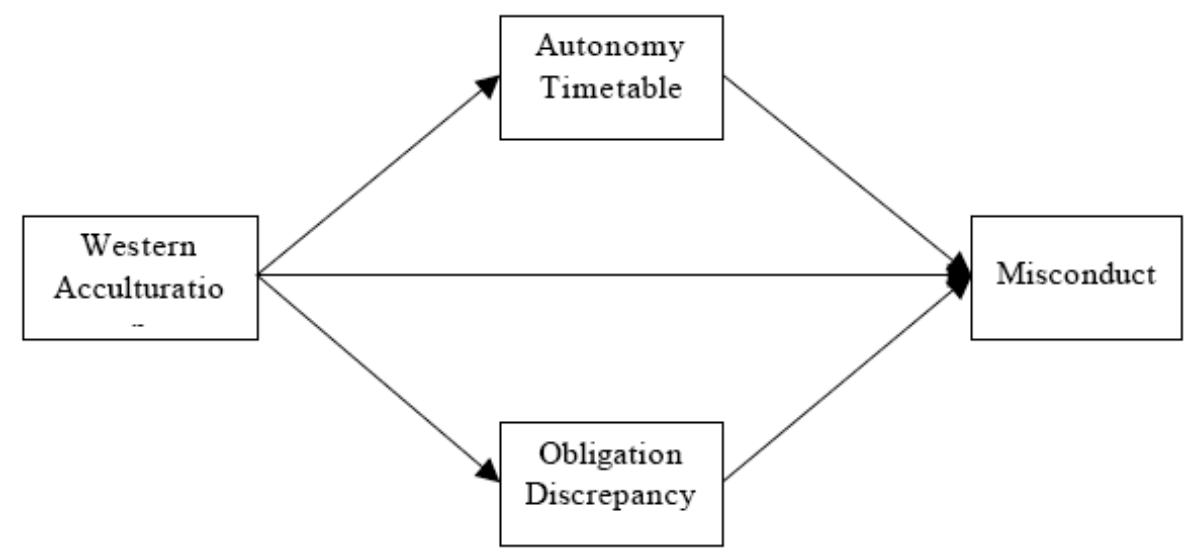

Fig. (1). The structure equation model derived from the significant correlations from Table $\mathbf{1}$.

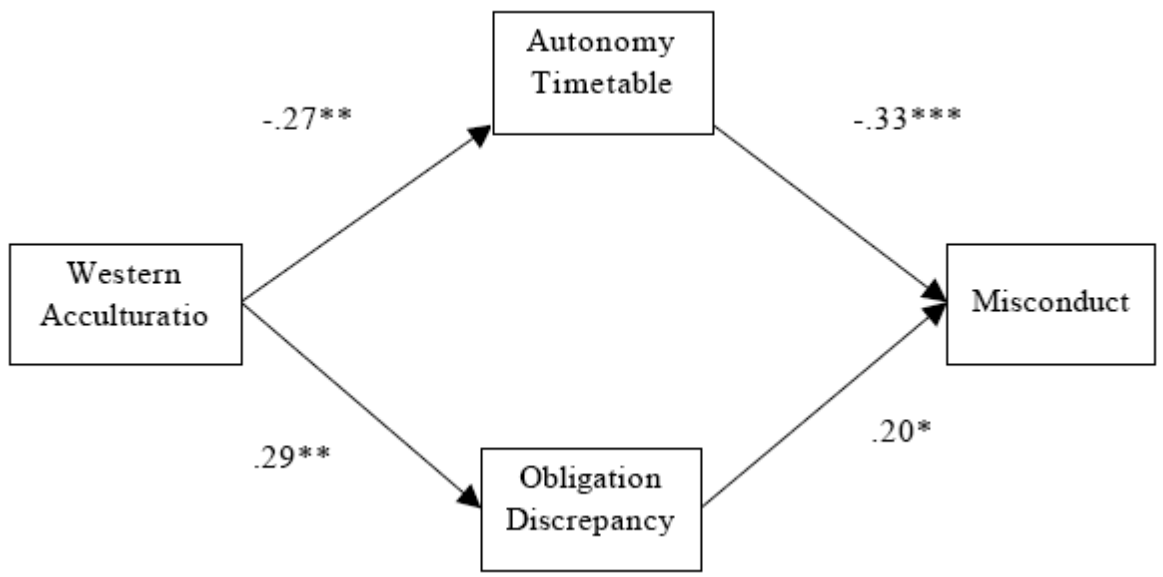

Fig. (2). The results of testing the structure equation model in Fig. (1) Note. ${ }^{*} p<.05,{ }^{*} p<.01,{ }^{* * *} p<.001$.

The model fitted well $\left(\chi^{2}(1, N=138)=0.131, p=.718\right.$, $\mathrm{CFI}=1.000)$ and the results are displayed in Fig. (2). The direct pathway between western acculturation and misconduct was no longer significant $(\beta=.14, p=.102)$, but both of the indirect pathways remained significant. This suggests that the influence of western acculturation on misconduct has been unpacked into two specific mechanisms. First, acculturated youths demanded earlier autonomy; second, they deviated from the expected family obligations. Both the demand and deviation led to more misconduct. Since the pathways were both significant in the final model, they exert relatively unique effects on misconduct.

\section{DISCUSSION}

As more societies undergo cultural transition, lessons learned from Hong Kong are pertinent. Hong Kong had a long colonial history and its society had more than a century to become westernized in a variety of domains, from religion to education [26]. Research findings that emerged from Hong Kong validated the prevalence of misconduct among 
youths who embrace western ideologies and styles of living. An overarching explanation, offered by Cheung-Blunden and Juang [9], is that when these youths become markedly different from their average peer, they become maladaptive to the local environment.

The strength and speed of westernization is much greater in many societies today than it was in Hong Kong. This accelerated pace means that westernized youths are at greater odds with their local setting, and the present study points to two ways these youths pull away from their peers - in terms of their elevated autonomy timetable and failure to fulfill family obligations. Insufficient parental supervision and family conflict in turn put the western acculturated youths at risk to develop problem behaviors. Of course, youths do not acculturate at a uniform rate even though they live in the same society under the same westernization pressure. Future studies are needed to explain the individual differences in acculturation rate, and identify the risk factors in communities, schools, peers and families.

Immigrant youths also struggle with autonomy and family obligations. Both of the factors have been studied under the umbrella of intergenerational differences, and these differences pave the way to family conflict and problem behavior. In other words, the effects of autonomy timetable and expectations of family obligation on misconduct overlap to some degree in immigrant settings. The case in colonial settings is different in the sense that these factors do not overlap as much. While greater obligation discrepancy may exert its effect through family conflict, early autonomy timetable exerts its influence through a lack of parental monitoring. Therefore, the two pathways remained relatively independent in the present study.

The implication for intervention is that problem behaviors among youths can be solved by tackling the two mediators. For example, one strategy is to facilitate earlier autonomy while mitigating the associated risks. Coed parties at a peer's house or a community center could offer youths some degree of autonomy. But, at the same time, event organizers and peer leaders may take on the monitoring roles of parents. Another intervention strategy could be to hone in on the differences in family obligations. Specifically, it is the differences between the levels of expectation that is the most harmful to familial harmony. In this sense, communication and negotiation skills are essential workshop topics for the entire family.

\section{Limitations}

There are several limitations to this study. One is the reliance on self-reports from only one source-the adolescent. It will be important in future studies to include other sources such as parents, especially for constructs dealing with family variables such as parent-adolescent discrepancy in family obligation. Another limitation is the correlational nature of the data. Although the structural equation model has a strong theoretical basis and the support of previous experimental data, future studies ought to test the causal nature of each of the pathways in the model in order to better inform intervention. Another limitation was recruitment of students from an all girl campus. Future studies are needed to test whether our findings are generalizable to boys as well as girls. Finally, one of the main limitations to our study is that we did not concurrently compare the Hong Kong sample with a sample from a society that has just opened up to western influences. The fast pace of acculturation may proven to be a more formidable force on adolescent adjustments than a more gradual acculturation process.

\section{CONFLICTS OF INTEREST}

\section{None Declared}

\section{ACKNOWLEDGEMENT}

The author wishes to thank Linda Juang, Thomas Spencer, Becky Loewy, George De Vos and Enrico Jones for their advice, Edmundo Angeles, Jeane Bosch and Miyuki Takagi for their assistance.

\section{REFERENCES}

[1] Pike KM, Borovoy A. The rise of eating disorders in Japan: issues of culture and limitations of the model of "westernization" Culture. Medicine Psychiatr 2004; 28: 493-531.

[2] Rissel C, McLellan L, Bauman A. Factors associated with delayed tobacco uptake among Vietnamese/Asian and Arabic youth in Sydney. Australian New Zealand J Public Health 2000; 24: 22-8.

[3] Stigler M, Dhavan P, Van Dusen D, Arora M, Reddy KS, Perry CL. Westernization and tobacco use among young people in Delhi, India. Soc Sci Med 2010; 71: 891-7.

[4] Woodward D, Drager N, Beaglehole R, Lipson D. Globalization and health: a framework for analysis and action. Bull World Health Organ 2001; 79: 875-81.

[5] Feldman SS, Rosenthal DA. The acculturation of autonomy expectations in Chinese high scholars residing in two Western nations. Int J Psychol 1990; 25: 259-81.

[6] Feldman SS, Rosenthal DA. Age expectations of behavioral autonomy in Hong Kong, Australian and American youth: the influence of family variables and adolescents' values. Int J Psychol 1991; 26: 1-23.

[7] Ramirez JM, Fung AL, Alvarado JM, Millana L. Justification of emotional and instrumental aggression in Hong Kong and Spanish University Students. Special Issue on Cultural issues in research of Aggression in Adolescents: international perspectives 2011.

[8] Arnett JJ. The psychology of globalization. Am Psychol 2002; 57: 774-783.

[9] Cheung-Blunden V, Juang LP. Expanding acculturation theory: are acculturation models and the adaptiveness of acculturation strategies generalizable in a colonial context? Int J Behav Develop 2008; 32: 21-34.

[10] Markus HR, Kitayama S. Culture and the self: Implications for cognition, emotion, and motivation. Psychol Rev 1991; 98: 224-53.

[11] Markus HR, Kitayama S. Culture and the self: Implications for cognition, emotion, and motivation. In: Baumeister RF, Ed. The self in social psychology. UK: Psychological Press 1999; 339-71.

[12] Arnett J, Balle-Jensen L. Cultural bases of risk behavior: Danish adolescents. Child Develop 1993; 64: 1842-55.

[13] Ary DV, Duncan TE, Biglan A, Metzler CW, Noell JW, Smolkowski K. Development of adolescent problem behavior. J Abnormal Child Psychol 1999; 27: 141-50.

[14] Barnes GM. Adolescent alcohol abuse and other problem behaviors: their relationships and common parental influences. J Youth Adolescence 1984; 13: 329-48.

[15] Feldman SS, Rosenthal DA, Mont-Reynaud R, Leung K, Lau S. Ain't misbehavin': adolescent values and family environments as correlates of misconduct in Australia, Hong Kong, and the United States. J Res Adolescence 1991; 1: 109-34.

[16] Juang LP, Nguyen HH. Misconduct among Chinese American adolescents: the role of acculturation, family obligation, and autonomy expectations. J Cross-Cultural Psychol 2009; 40: 649-66. 
[17] Stewart SM, Bond MH, McBride-Change C, Fielding R, Deeds O, Westrick J. Parent and adolescents contributors to teenage misconduct in Western and Asian high school students in Hong Kong. Int J Behav Develop 1998; 22: 847-69.

[18] Chen C, Greenberger E, Lester J, Dong Q, Guo MS. A crosscultural study of family and peer correlates of adolescent misconduct. Develop Psychol 1998; 34: 770-81.

[19] Kim U, Choi SH. Individualism, collectivism, and child development: a Korean perspective. In: Greenfield PM and Cocking RR, Eds. Cross-cultural roots of minority child development. New Jersey: Erlbaum 1994; pp. 227-57.

[20] Lee RM, Choe J, Kim G, Ngo V. Construction of the Asian American family conflicts scale. J Counsel Psychol 2000; 47: 211-22.

[21] Portes A, Rumbaut RG. Immigrant America: a portrait. 2nd ed. Berkeley and Los Angeles, CA: University of California Press 1996.
[22] Education and Manpower Bureau. Press releases and publications. 2006. Available from http://www.emb.gov.hk/index.aspx?node ID $=1039 \&$ langno $=1$

[23] Nguyen HH, Messé LA, Stollak GE. Toward a more complex understanding of acculturation and adjustment. J Cross-Cultural Psychol 1991; 30: 5-31.

[24] Juang LP, Lerner JV, McKinney J, von Eye A. The goodness of fit in autonomy timetable expectations between Asian-American late adolescents and their parents. Int J Behav Develop 1999; 23: 102348.

[25] Fuligni AJ, Tseng V, Lam M. Attitudes toward family obligations among American adolescents with Asian, Latin American, and European backgrounds. Child Develop 1991; 70: 1030-44.

[26] Chan H, Leung JY. Education. In: Wilding P, Huque AS, Tao JL, Eds. Social policy in Hong Kong. Cheltenham, UK: Edward Elgar 1997; pp. 55-71.

(C) Violet Cheung-Blunden; Licensee Bentham Open.

This is an open access article licensed under the terms of the Creative Commons Attribution Non-Commercial License (http://creativecommons.org/licenses/by-nc/3.0/) which permits unrestricted, non-commercial use, distribution and reproduction in any medium, provided the work is properly cited. 